\title{
METALLOGRAPHIC ETCHING REAGENTS: I, FOR COPPER
}

\author{
By Henry S. Rawdon and Marjorie G. Lorentz
}

\section{CONTENTS}

Page

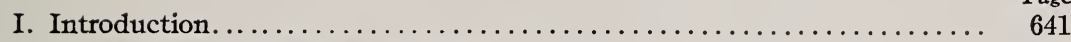

II. Types of copper used as specimens $\ldots \ldots \ldots \ldots \ldots \ldots \ldots \ldots \ldots \ldots, 643$

III. Nature of the etching process........................... 644

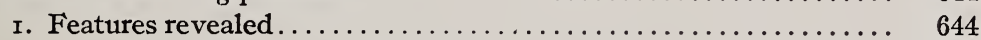

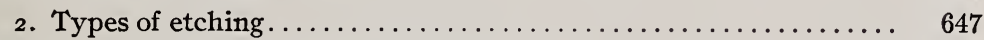

IV. Importance of oxidation in the etching of copper. . . . . . . . . . . 650

V. Typical etching reagents and results obtained . . . . . . . . . . . . . 656

VI. Discussion . . . . . . . . . . . . . . . . . . . . . . . . . . . . . . . . 665

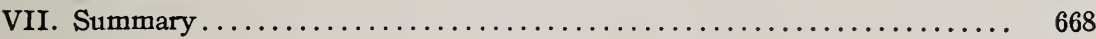

\section{INTRODUCTION}

One of the prime requisites for success in the study of the microstructure of metals is a satisfactory method of etching the polished surface. In the one-constituent or single-phase alloys this is absolutely essential, though when dealing with those of a duplex or more complex structure, there is usually enough difference in the mechanical properties of the different constituents to reveal many of the structural features by merely continuing the polishing for a sufficiently long period. The technique of the preparation of metal specimens for microscopic study must be learned by experience; the matter of etching, however, seems to have been developed largely in an empirical manner, the chemical nature of the different metals and alloys being used in a general way as a guide.

Although the technique of etching has been rather well developed, little detailed information on the general subject exists in the technical literature aside from the specific information usually embodied in the description of any study of the microscopic features of any particular alloy or metal. Most of the special contributions to the subject of etching have been for the purpose of describing new etching methods and reagents. As 


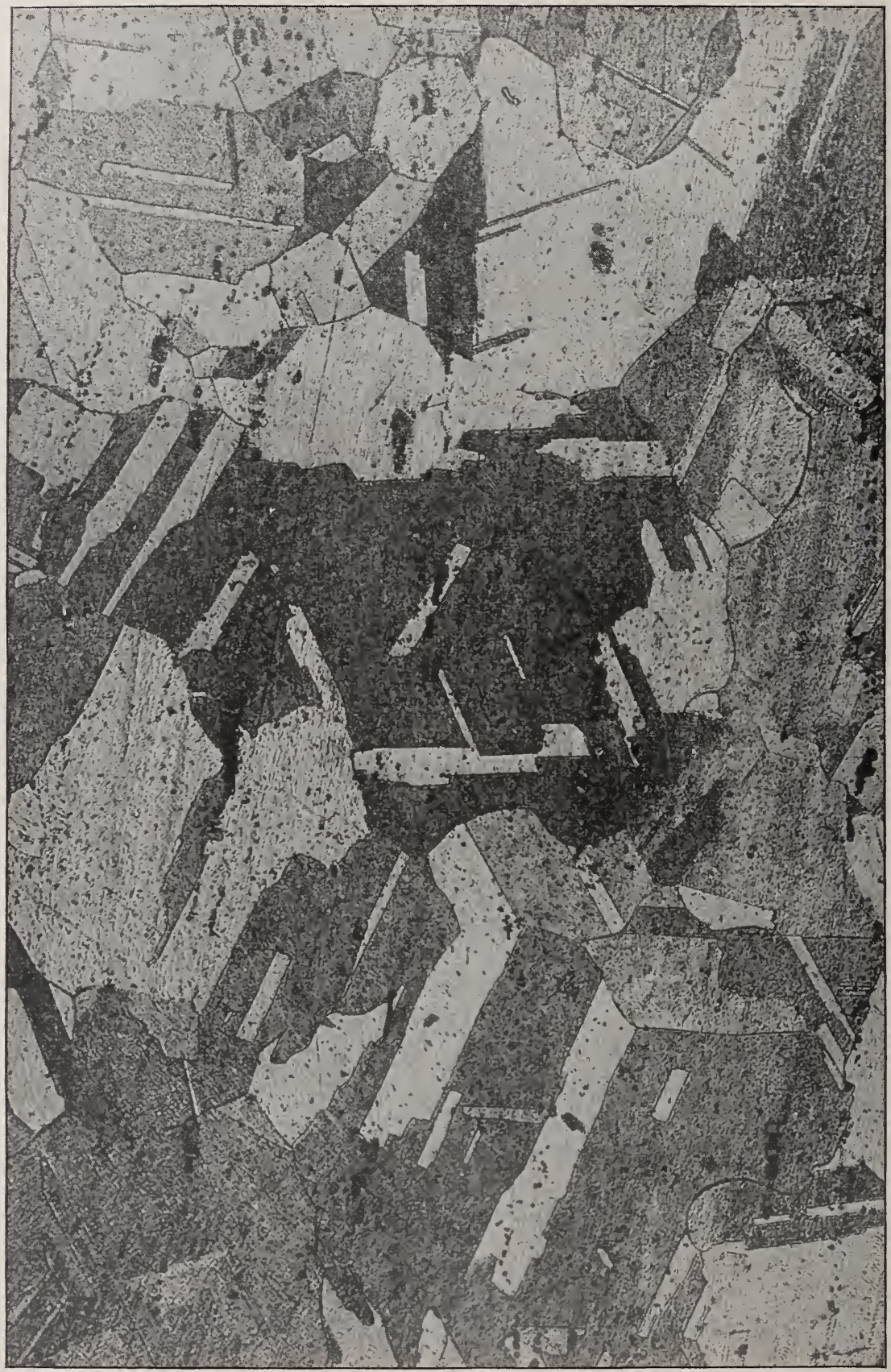

Fig. I.-Structure of hot-rolled copper as revealed by etching with an ammoniacal solution of copper ammonium chloride. $\times 250$ 
typical of these may be mentioned the work of Stead, ${ }^{1}$ of Rosenhain and Haughton, ${ }^{2}$ and of LeChatelier and Bogitch. ${ }^{3}$

The descriptions which have been published on the general subject of metallographic etching consist mainly of compilations of the experience and opinions of workers engaged in metallographic work rather than the result of any systematic study of the subject. Among these articles may be mentioned that of Hudson, ${ }^{4}$ of Guertler, ${ }^{5}$ and of Czochralski . ${ }^{6}$ In the third article the subject is treated in the most comprehensive manner, the first two being mainly compilations of current practice in metallographic etching.

On account of the dearth of information concerning metallographic etching reagents and methods, a study of the general subject was deemed advisable and was undertaken by this Bureau. The aim is to establish, wherever possible, the principles which underlie the successful methods of etching. It was also anticipated that valuable data might be obtained incidentally relating to the characteristic properties, other than the etching characteristics, of the microstructural constituents of the various alloys used as types. The discussion which follows relates to the results obtained with copper, which was the first type to be considered. Copper was chosen as a starting point in the investigation for two reasons, (I) on account of the technical importance of the metal itself, and (2) because of the fact that it enters into the composition of a large number of commercial alloys. In a general way the etching properties of metallic copper are quite characteristic of the behavior of its single-phase or one-constituent alloys in respect to etching.

\section{TYPES OF COPPER USED AS SPECIMENS}

As materials for study specimens of copper representative of five different physical conditions were used. These included cast, hot-rolled, annealed (after cold work), and cold-drawn material, as well as electrolytic (cathode) copper. On account of the high purity of refined copper, even of the commercial grades, ${ }^{7}$ a chemical analysis of the materials used was deemed unnecessary.

\footnotetext{
${ }^{1}$ J. E. Stead, Iron, Carbon, and Phosphorus, Jour. Iron and Steel Inst., 91, p. I73, I9I 5.

${ }^{2}$ W. Rosenhain and J. L. Haughton, A New Reagent for Etching Mild Steel, Jour. Iron and Steel Inst., 89 , p. 5 I 5 ; 1914.

${ }^{3}$ H. LeChatelier and B. Bogitch, Macrography of Steel, Etching Tests, Rev. Met., 16, p. I29; r9I9.

${ }^{4}$ O. F. Hudson, Etching Reagents and Their Application, J. Inst. Metals, 13; 1915.

${ }^{5}$ W. Guęrtler, Etching Reagents, Int. Zeit. Metallographie, 8; г9ı6.

${ }^{6} \mathrm{~J}$. Czochralski, The Principal Etching Phenomena and the Metallographic Etching Process, Stahl und Eisen, 35, pp. 1073-1078, I129-II35; 1915.

${ }^{7}$ B. S. Circular No. 73. Copper, pp. ro-rx.
} 
The cathode copper used was a sample of the metal used as a standard for the determination of thermometric fixed points ${ }^{8}$; the metal is of exceptionally high purity ( 99.987 per cent copper). A specimen of rather high oxide content was chosen as representative of the cast material in order to accentuate the possible influence of the oxide upon the etching. The hot-rolled and the annealed materials were from one-fourth-inch strips intended for electrical purposes, and a section of a trolley wire of three-eighthsinch diameter was used as representative of the cold-worked state.

\section{NATURE OF THE ETCHING PROCESS}

\section{FEATURES REVEALED}

In the case of the "pure" metals and of the one-constituent alloys the main features revealed by etching, aside from inclusions of a foreign or nonmetallic nature and similar extraneous substances, are the grain or crystal size and arrangement and the internal condition or "make-up" of such grains. Of course, if the metal has been contaminated by alloying with other substances, so that it can not be properly referred to as "pure" metal, other features are often revealed. In Fig. I the usual structural features of copper as exhibited by the metal in the hot-rolled state are shown. Besides showing the usual features of the structure of copper, the micrograph illustrates the use of one of the most satisfactory of the various reagents which are used for etching copper.

The features characteristic of the structure of any metal are seldom revealed by a single etching. In most cases it is best to etch the material in a series of stages, as some of the features are revealed only after a rather severe attack, which at the same time obliterates or obscures other features which are best seen after a slight etching. Fig. 2 shows a specimen etched in a series of four stages with ammonium persulphate, the same area being used in each case. The same specimen, though not the same spot as in Fig. 2, is shown in Fig. 3, after a similar series of etchings in nitric acid. The dissolving of the surface metal occurs in a very definite manner, and is the inverse of the process by which the crystalline structure was initially built up. This, as well as the fact that the crystals do not all dissolve at the same rate, is well shown in Fig. 2. This difference in the rate of solution is due in all probability to the orientation of sectioning plane through the internal structure

${ }^{8}$ B. S. Circular No. 66, Standard Samples for Thermometric Fixed Points, p. 8. 


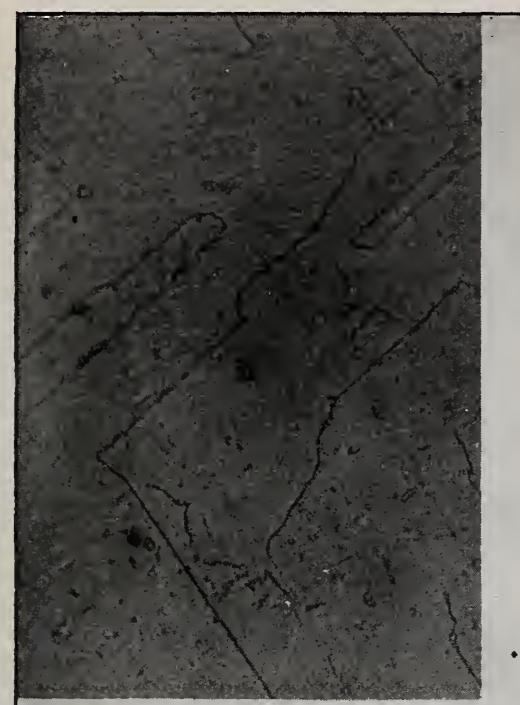

a

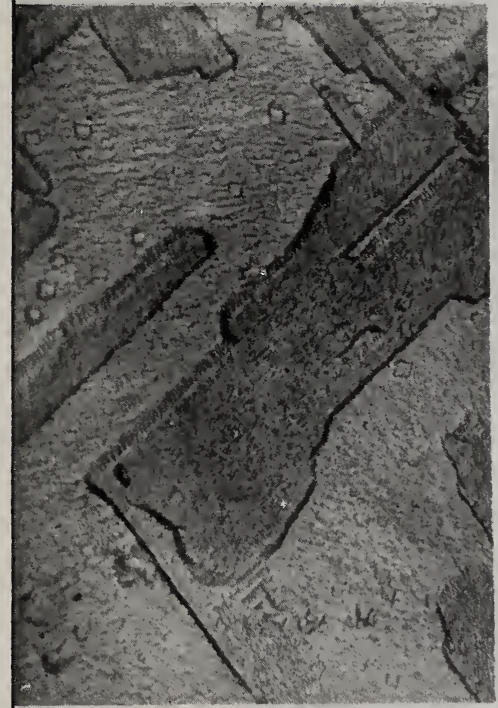

$c$

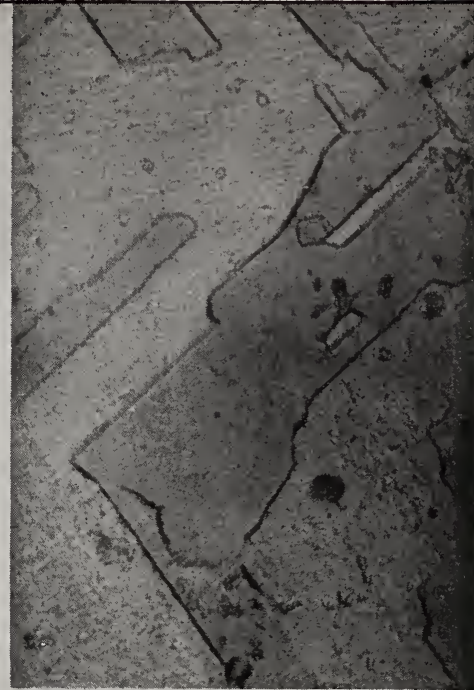

6

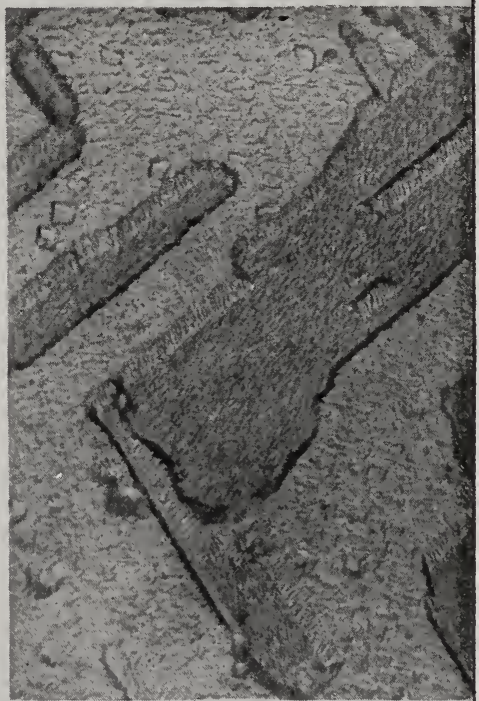

$d$

FIG. 2.-Structure of hot-rolled copper revealed by progressive etching with a Io per cent solution of ammonium persulphate. $\times 500$

$c$ and $d$ illustrate good practice for developing etching pits. Etching period: $a, \mathrm{I}$ minute; $b, \mathrm{I}$ minute, 30 seconds; $c, 2$ minutes, ro seconds; $d, 3$ minutes 


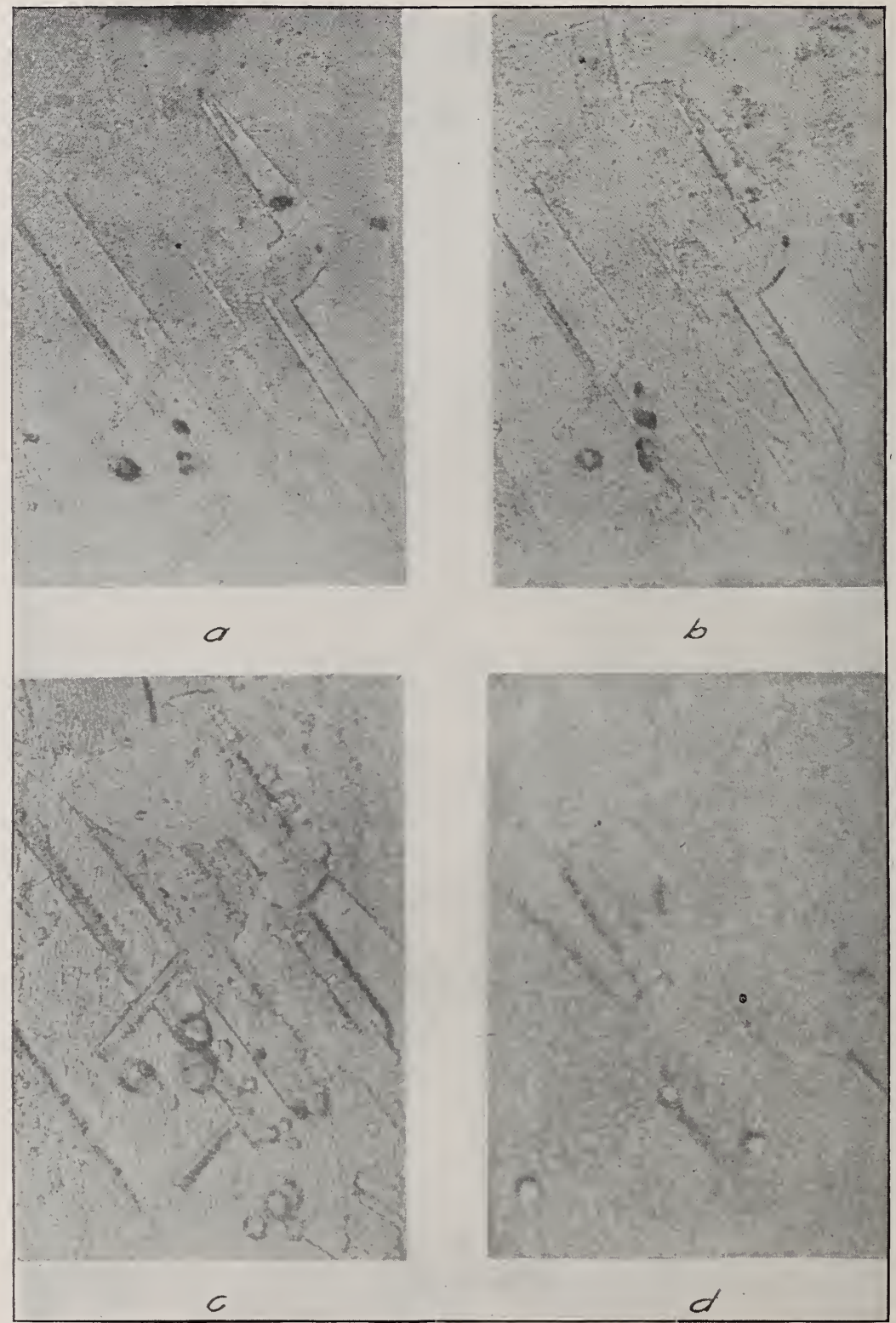

FIG. 3.-Structure of hot-rolled copper revealed by progressive etching with dilute nitric acid ( $I$ to $I$ ). $\times 500$

Ftching period: $a, 15$ seconds; $b, 45$ seconds; $c$, I minute, 45 seconds; $d, 2$ minutes, 45 seconds 
of the individual crystals. The variation in level of the surface produced by the difference in the rate of solution of adjacent grains in ammonium persulphate is well shown in Fig. 2, $c$ and $d$. With nitric acid, however, the action occurs so readily that the etching can not be controlled easily, and a very rough surface results in which most of the evidence revealed by light etching is obliterated.

\section{TYPES OF ETCHING}

For convenience in discussion, the difference in the appearance of the surface of specimens after different methods of etching will will be referred to as different types of etching, although, as shown below, the same etching reagent by proper manipulation may be used for producing more than one type of etched surface. The two principal types will be designated as "plain" and "contrast"; these are readily distinguished from one another, as illustrated by Fig. 7. In most cases after a moderate attack the plain etching reveals principally the crystal boundaries, all the crystals appearing very much the same, aside from the differences in their shape and size. With contrast etching, on the other hand, there is a marked difference between crystals, so that a sharp brilliant contrast is obtained. The two types are relative only, and all graduations between the two extremes readily occur in practice. The simple or plain etching may be carried out by any reagent which dissolves a very thin surface layer of metal and is not accompanied by other effects such as are described below for the type of contrast etching. Advantage may also be taken of the electrochemical nature of copper with respect to other metals to produce this type of etching. The specimen may be immersed in a solution of a salt of a metal which is more electronegative than copper, such as silver, which is the most convenient one to use. After such etching, it is necessary to remove the film of precipitated metal, which can usually be done very readily with a swab of soft cotton. Specimens may also be etched electrolytically in a suitable (usually neutral) solution by means of an applied electromotive force of low voltage; the specimen forms one electrode (usually anode), the other being of platinum or some other suitable resistant metal.

The characteristic feature of the second or contrast type of etched surface is very often due to a thin film which forms selectively on certain crystals, though the same effect may be produced by the difference in manner and rate of the solution of the $8057^{\circ}-20-2$ 


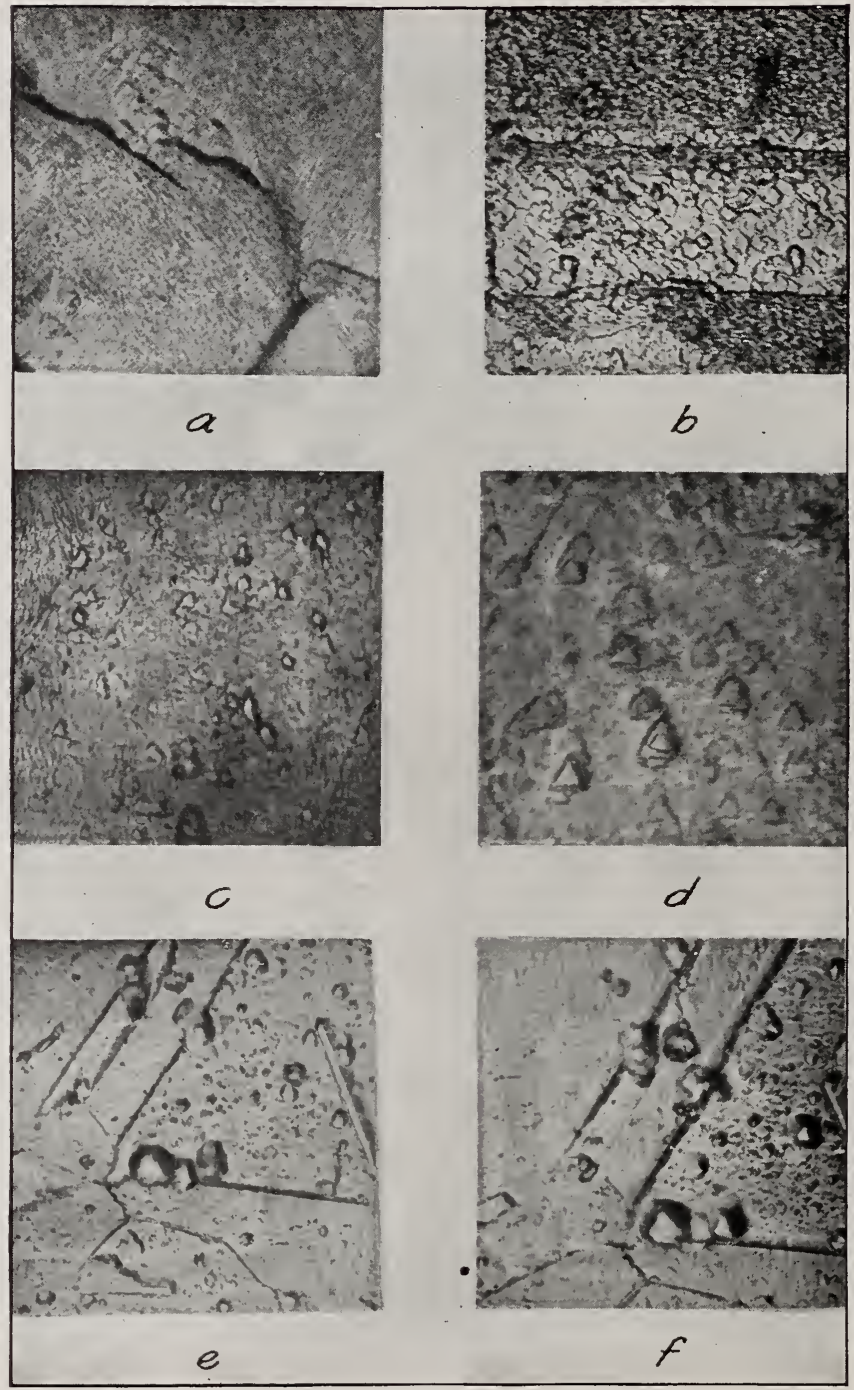

FIG. 4.-Minute structure (etching pits) of hot-rolled copper revealed by various etching reagents. $\times 500$

The same specimen was used throughout, though not the same spot, except for $e$ and $f$. Etching reagents: $a$, dilute sulphuric acid containing potassium permanganate ( 4 , Table $I) ; b$, acidified solution of ferric chloride $(5$, Table 1 ); $c$, aqueous solution of copper ammonium chloride ( $1_{3}$, Table 1 ); $d$, dilute sulphuric acid containing potassium dichromate ( 3 , Table $I) ; e$, ammonium hydroxide and hydrogen peroxide (I, Table $\mathrm{r}$ ); $f$, same as $e$ after deeper etching 


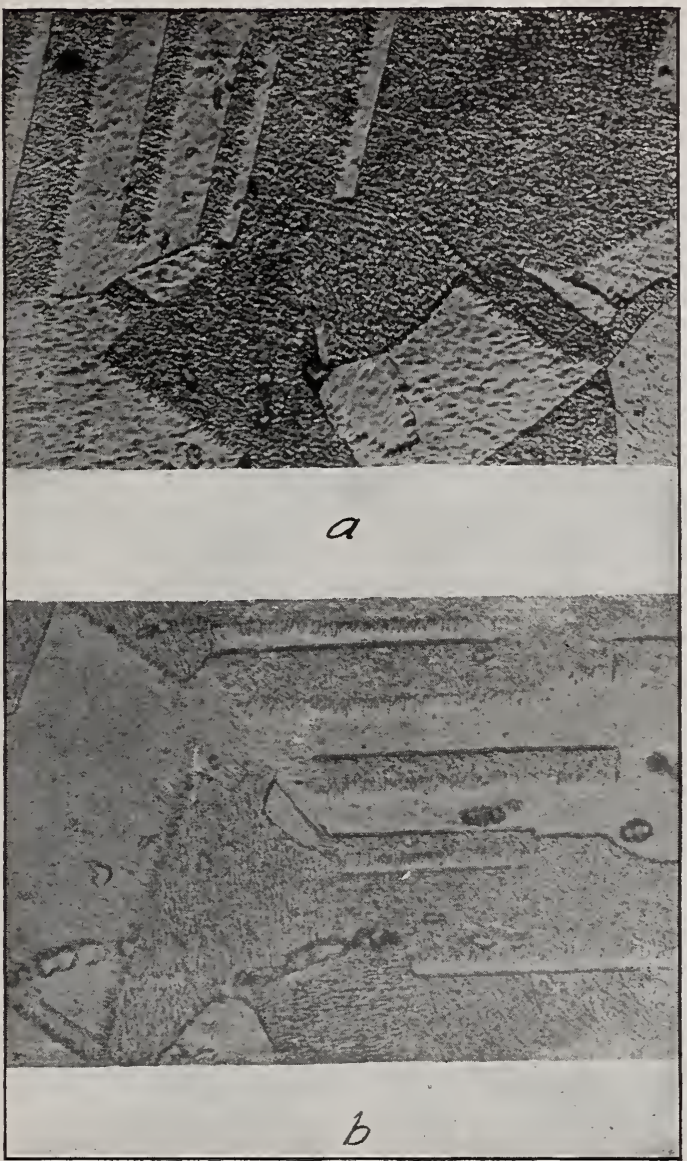

FIG. 5.-Selective attack of different crystals of hotrolled copper when etched. $\times 500$

Some of the crystals are much more vigorously attacked than others, so that a difference of level results. This is indicated by the straight line along one edge of a crystal, while the opposite side shows the slope between two adjacent crystals. This appearance is probably due to the fact that the rays of light were not perfectly normal to the etched surface. $b$ represents the same area as $a$ after rotating the specimen through $90^{\circ}$. Ftching reagent, ammoniacal solution of copper ammonium chloride 
metal of the various crystals. As shown in Figs. 4 and 5 the type of pits produced by the solvent action of the etching reagent varies considerably in the different crystals, some having a fine stippled appearance due to the roughening produced by tiny pits, while others have a smoother surface and apparently are not dissolved as rapidly as the other crystals. This difference is undoubtedly due to the orientation of the sectioning plane of the specimen to the structure of the various crystals. That the difference between such crystals is a real one and not merely apparent, such as is observed when an etched specimen is observed under oblique illumination, is evident from the fact that the illumination used for all the observations is normal to all of the crystals. The same relative difference of appearance between the different crystals also persists as the specimen is rotated on the stage of the microscope (Fig. 5). The selective production of a thin film upon certain crystals is responsible for much of the contrast effect produced in the etching of copper. This is largely a matter of oxidation and is discussed in detail in the following section.

\section{IMPORTANCE OF OXIDATION IN THE ETCHING OF COPPER}

Ammonium hydroxide is one of the most common reagents used for the etching of copper. Contrary to the general opinion, copper is not readily etched by ammonium hydroxide alone. Immersion in the concentrated solution for a period of one hour was not sufficient to etch a specimen to any appreciable extent, as is shown by Fig. 6, $a$. By an immersion of 17 hours a certain degree of etching was produced; the general effect, however, was quite unsatisfactory, as Fig. $6, b$ shows. The principal effect of short immersion in the etching solution, for example, one hour, appears to be a pitting of the surface as the inclosed specks of cuprous oxide, which are always present to some extent in copper that has been melted, are dissolved. This is due to the greater solubility of the oxide as compared to that of the metal. If a gentle stream of oxygen is bubbled through the concentrated ammonium hydroxide and directed against the immersed specimen, the etching is very active. However, only the area in direct contact with the oxygen bubbles is etched, as is shown by Fig. 6, $c$ and $d$, which shows the appearance of two spots about one-eighth of an inch apart, on one of which, $c$, a very fine stream of oxygen bubbles was directed for five minutes, while the other was exposed to the action of the concentrated ammonium hydroxide alone. 


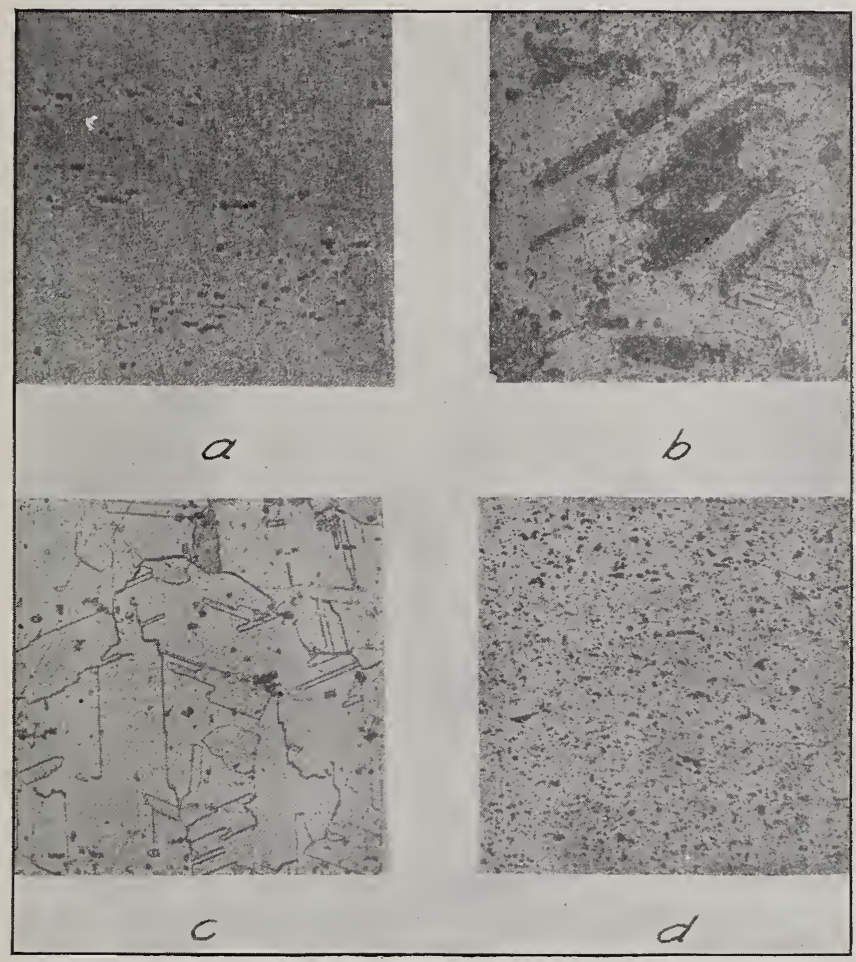

Fig. 6.-Influence of oxidation upon the etching of hot-rolled copper with concentrated ammonium hydroxide. $\times 100$

Etching conditions: $a$, I hour's immersion; $b$, I7 hour's immersion; $c, 5$ minutes; a fine stream of oxygen was directed against the spot shown while the specimen was immersed; $d$, same specimen as $c$. The spot shown was at a distance of $1 / 8$ inch from $c$; no bubbles of oxygen reached this area 
A certain amount of solvent action is always necessary in contrast etching in order to reveal the individual grains, but the characteristic appearance is due to the surface film. Dry oxygen does not attack copper readily; the moist gas is somewhat more active. If traces of acid or ammonia fumes are present, the oxidation is very much accelerated. The polished surface of a specimen of copper was only slightly dimmed after 20 minutes' exposure in moist oxygen; that is, gas taken directly from the cylinder of compressed gas. A very similar result was produced by bubbling a gentle stream of oxygen through distilled water for I 5 minutes against the polished surface of a specimen of hot-rolled copper immersed in the water. However, when traces of ammonia fumes were introduced into a vessel of oxygen and a polished specimen of copper was placed within, a pronounced film formed within five minutes. The action was much more vigorous when the specimen was dipped for an instant in concentrated ammonia before being placed in the atmosphere of oxygen. In all these cases, however, the film which was formed was a continuous one and no evidence of the structure of the metal was obtained, thus emphasizing the need of a slight dissolving of the metal to accompany the oxidation. Not only must the "flowed metal, "due to the polishing of the surface layer be removed, but a certain amount beneath this must be dissolved.

As stated above, by proper manipulation the same etching reagent may be used to produce either of the two types of etched surfaces, as desired. This is well illustrated by the use of ammonium hydroxide and an oxidizing agent, hydrogen peroxide, the mixture being one of the most widely used reagents for the etching of copper. Fig. 7 illustrates the results obtained. By keeping the ammonium hydroxide in excess, a plain uncontrasted etching was produced; when, after etching, the specimen was dipped for an instant into hydrogen peroxide, a pronounced film of oxide resulted, which was readily detected by the change in color of the surface. There was, however, no selective oxidation by this method, and no contrast was produced, as shown by Fig. $7, b$. The details revealed by the previous etching (Fig. 7,a) are merely obscured somewhat by the oxidation which occurred.

If the relative proportions of ammonium hydroxide and hydrogen peroxide are changed, however, so that the oxydizing agent is in considerable excess, selective oxidation of the various crystals supplements the solvent action, and a "contrast etching" results. 
Scientific Papers of the Bureau of Standards, Vol. 16

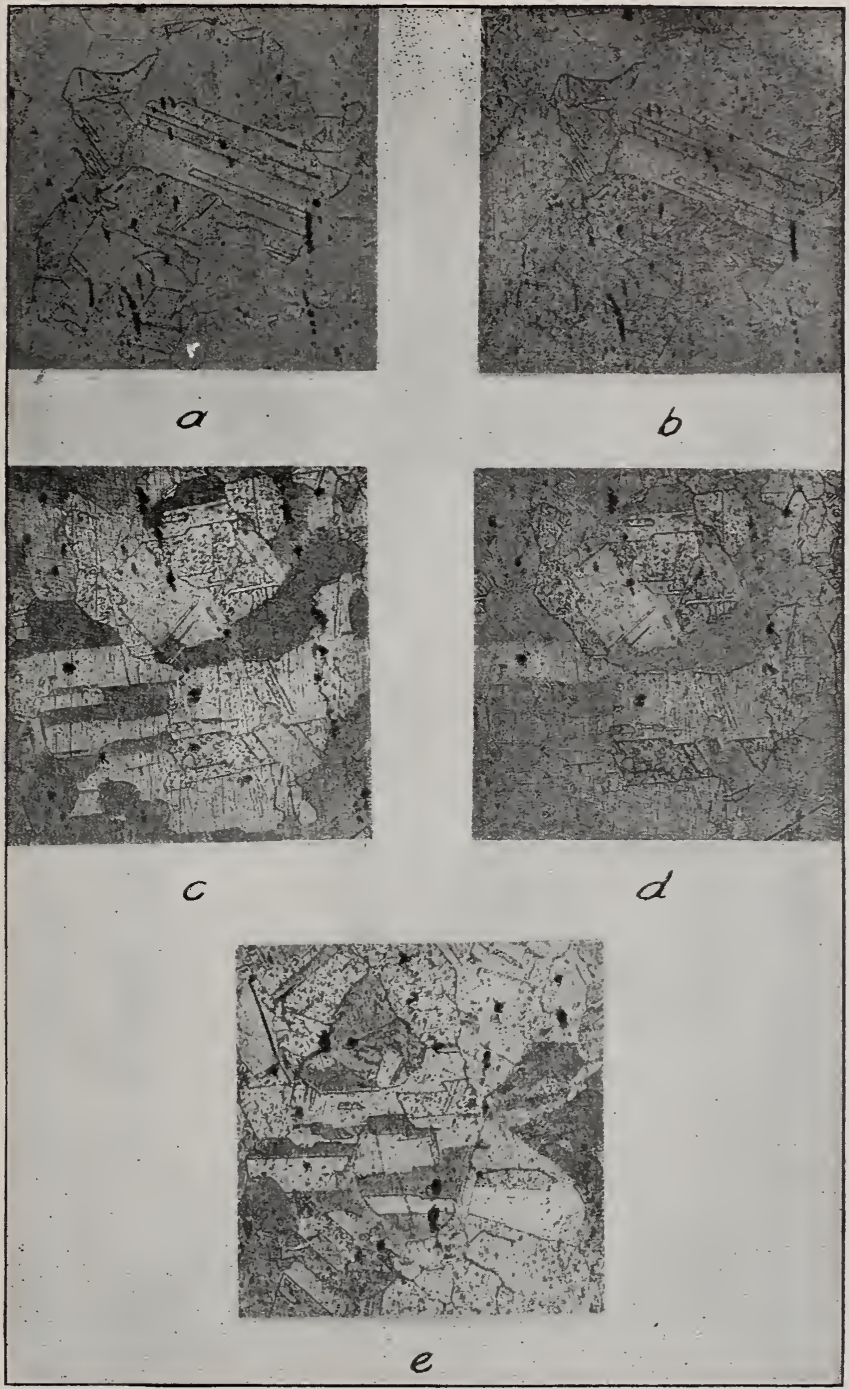

FIG. 7.-Influence of oxidation upon the etching of hot-rolled copper with ammonium hydroxide. XIOO

Etching conditions: $a$, Ammonium hydroxide and hydrogen peroxide, I-I ( $\mathrm{I}$, Table I). $b$, Specimen $a$ was dipped after etching into hydrogen peroxide. A pronounced film of oxide formed upon the surface. No selective oxidatior of individual crystals was produced in this way. $c$, The specimen was etched in a mixture of 20 parts of hydrogen peroxide to 1 part concentrated ammonium hydroxide. Selective oxidation, under these conditions, accompanied the etching of the specimen. $d$, Same as specimen $c$. The oxide film was removed by immersing the specimen in concentrated ammonium hydroxide. $e$, The specimen was rubbed with a swab of cotton saturated with concentrated ammonium hydroxide and then allowed to oxidize by exposure to the air 
This is shown in Fig. 7,c, the oxide film, however, was readily removed by an instant's immersion in the concentrated ammonium hydroxide, as illustrated by Fig. 7, $d$. Micrograph $e$ of the'same figure illustrates a modification of the method of etching with ammonium hydroxide; the specimen, after being rubbed with a swab of cotton saturated with the hydroxide, was exposed to the air so as to permit the selective oxidation of crystals to occur. While excellent results are often obtained by this means, the method has the obvious disadvantage that it is largely a matter of chance.

The importance of oxidation in the etching of copper is well illustrated by the use of solutions which are usually considered to havể but slight solvent effect upon the metal. Fig. 8 illustrates this. A ro per cent aqueous solution of ammonium chloride, prepared by the use of distilled water which had been boiled to expel all gases, produced no etching on polished specimens of hot-rolled copper during a 6-hour immersion, other than a slight pitting of the surface. A solution of similar concentration which had been exposed to the air for several days produced a noticeable etching effect after an immersion of $\mathrm{I} / 2$ hours (Fig. 8, $a$ ), while an immersion period of 15 minutes in a similar solution through which oxygen was bubbled while the specimen was immersed was sufficient to produce a very decided etch (Fig. 8, b). Neutral solutions of ammonium sulphate behave similarly (Fig. 8, $c$ and $d$ ). A Io per cent solution of sodium chloride was also tried. When a gentle stream of oxygen bubbles was directed against the polished surface of a specimen of hot-rolled copper, a very pronounced film of oxide formed in 8 minutes over the area exposed to the oxygen. No trace of etching was found, however, thus emphasizing the fact that only those solutions, such as ammonium salts, that have a slight solvent action on the metal can be used as etching reagents.

Dilute sulphuric acid solutions alone have little or no effect upon copper. The addition of oxygen, however, renders such solutions fair etching reagents. A polished specimen, after being immersed in a ro per cent aqueous solution of sulphuric acid for a period of 30 minutes, showed no trace of etching. However, when oxygen was bubbled through the solution, the specimen being immersed during the time, the metal was lightly etched in 5 minutes, as shown in Fig. 8, $e$. The use of dilute acid solutions containing oxidizing reagents is discussed further in the following section. 


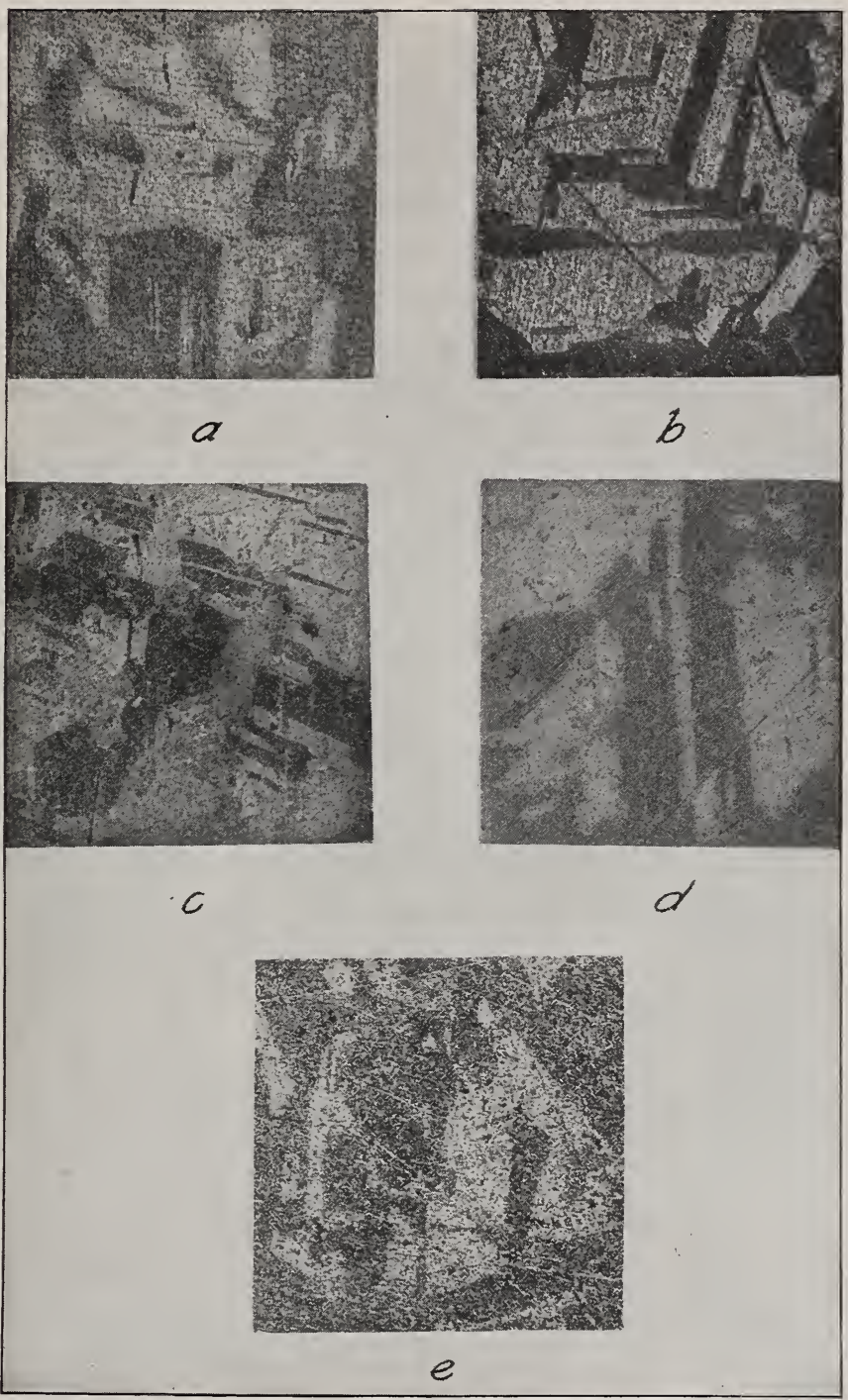

FIG. 8.-Influence of oxidation upon the etching of hot-rolled copper with neutral solutions of ammonium salts and with dilute acid. $\times 100$

Etching conditions: $a$, Io per cent ammonium chloride solution which had been exposed to the air for several days; etching period, approximately $\mathbf{x}^{1} / 2$ hours. $b$, to per cent ammonium chloride, through which oxygen was bubbled; etching period, I5 minutes. $c$, Io per cent ammonium sulphate solution, through which oxygen was bubbled. The stream of gas was directed against the area shown in $c$; etching period, approximately to minutes. $d$, Same as $c$; the area shown was out of the path of the stream of gas. $e$, 10 per cent sulphuric acid, through which oxygen was bubbled; etching period, to minutes 
That the formation of the oxide film upon certain crystals in preference to the neighboring ones is not a matter of chance may be demonstrated by repeatedly etching a specimen under similar conditions and noting the behavior of certain crystals after each etching. This is illustrated by Fig. 9. A specimen of hot-rolled copper was etched with a mixture of ammonium hydroxide and hydrogen peroxide so as to produce a contrast etch. After photographing, all traces of the oxide film were removed by means of concentrated ammonium hydroxide; the specimen was etched a second time so as to produce a contrast etch, and the same area of the specimen was rephotographed. This operation was repeated several times. It was found that in any particular area the same crystals are always darkened by the etching, thus indicating that the selective oxidation is due to inherent differences of properties of such crystals as compared with the adjacent ones which remain bright and comparatively free from the oxide film. In most cases the degree of contrast produced by the initial etching is more pronounced than that in the subsequent etchings. By rather deeply etching the specimen, it may be shown that the crystals upon which the oxide films form during contrast etching are the ones which are the most roughened by the solvent action of the more active etching reagents, thus adding further evidence that the behavior of the crystals during etching is a characteristic one and not one of chance. Presumably the variation in the electrochemical properties of the crystals of copper in different directions is the fundamental reason for the difference in etching characteristics. The influence of oxidizing agents in increasing the rate of solution of metals by acids has been described by Watts and Whipple. $^{9}$ The increase in the loss of weight of specimens immersed in the various mixtures of acid and oxidizers was used as a measure of the influence of the oxidizer. The results obtained were of the same character as those described here.

\section{TYPICAL ETCHING REAGENTS AND RESULTS OBTAINED}

Below are given micrographs of copper of the five types used, showing the behavior of various etching reagents upon copper to illustrate the principles discussed in the foregoing sections (Figs. IO-I4, inclusive). In Table I below, the compositions of the various solutions as well as information concerning the etching

${ }^{9}$ O. P. Watts and N. D. Whipple, Corrosion of Metals by Acids, Trans. Am. Electrochem Soc., 32, p. 257,1917 . 


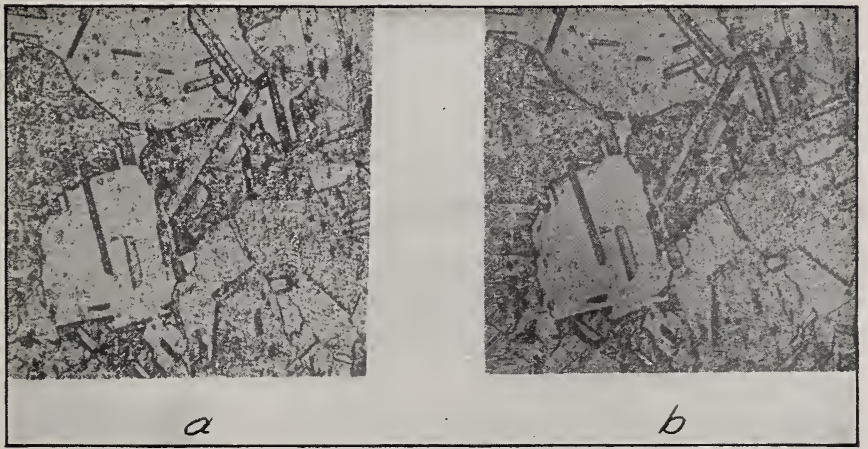

FIG. 9.-The characteristic selective oxidation of different crystals during the contrast-etching of hot-rolled copper with an ammoniacal oxidizing solution. $\times 100$

The specimen was repeatedly etched with a mixture of concentrated ammonium hydroxide and hydrogen peroxide $(x-20)$, the film of oxide which covered certain of the crystals being removed with concentrated ammonium hydroxide before each new etching. The same crystals are always darkened by the etching, it is not a matter of chance. In the two micrographs, $a$ and $b$, the same crystals are darkened in the later stage, $b$, as in the earlier one, $a$ 
are given. The solutions listed in the table are intended as types illustrative of the principles given in the foregoing sections rather than a complete reference table in any sense of the word.

TABLE 1.-Typical Etching Reagents for Copper

\begin{tabular}{|c|c|c|c|c|}
\hline No. & Type & Composition $a$ & $\begin{array}{l}\text { Approximate } \\
\text { etching period }\end{array}$ & Remarks \\
\hline 1 & $\begin{array}{l}\text { Ammonia plus oxi- } \\
\text { dizer }\end{array}$ & $\begin{array}{l}\text { Equal volumes concentrated } \\
\text { ammonium hydroxide and } \\
\text { hydrogen peroxide ( } 3 \mathrm{per} \\
\text { cent solution) }\end{array}$ & $5-15$ seconds... & $\begin{array}{l}\text { By proper manipulation a con- } \\
\text { trast etch can be produced. } \\
\text { See text below. Very satis- } \\
\text { factory as shown (Fig. } 6 a \text { ) } \\
\text { for examination at high } \\
\text { magnification }\end{array}$ \\
\hline 2 & Acid plus oxidizer... & $\begin{array}{l}1 \text { part concentrated sulphuric } \\
\text { acid (sp. gr. } 1.84 \text { ) and } 20 \\
\text { parts hydrogen peroxide ( } 3 \\
\text { per cent solution) }\end{array}$ & $1-1 \frac{1}{2}$ minutes. & \\
\hline 3 & $\ldots . d o \ldots$ & $\begin{array}{l}1 \text { part concentrated sulphuric } \\
\text { acid (sp. gr. 1.84) in } 10 \\
\text { parts saturated solution of } \\
\text { potassium dichromate }\end{array}$ & $30-60$ seconds... & $\begin{array}{l}\text { This method emphasizes the } \\
\text { occurrence of the cuprous } \\
\text { oxide inclusions }\end{array}$ \\
\hline 4 & ....do.. & $\begin{array}{l}1 \text { part concentrated sulphuric } \\
\text { acid (sp. gr. } 1.84 \text { ) to } 10 \\
\text { parts of solution potassium } \\
\text { permanganate ( } 4 \mathrm{~g} \text { per } 1000 \\
\mathrm{~cm}^{3} \text { water) }\end{array}$ & $1-11 / 2$ minutes.. & \\
\hline 5 & ....do.. & $\begin{array}{l}10 \mathrm{~g} \text { ferric chloride, } 30 \mathrm{~cm}^{3} \\
\text { hydrochloric acid (sp. gr. } \\
1.19), 120 \mathrm{~cm}^{3} \text { water }\end{array}$ & 30 seconds. & $\left\{\begin{array}{l}\text { Both methods are very satis- } \\
\text { factory for examinations at } \\
\text { lower magnifications, but } \\
\text { not for high magnifications. }\end{array}\right.$ \\
\hline 6 & $\ldots$...do... & Same, in $120 \mathrm{~cm}^{3}$ alcohol... & .....do... & $\begin{array}{l}\text { The alcoholic solution pro- } \\
\text { duces the better contrast }\end{array}$ \\
\hline 7 & $\begin{array}{l}\text { Ammonia plus oxi- } \\
\text { dizer }\end{array}$ & $\begin{array}{l}1 \text { part concentrated ammoni- } \\
\text { um hydroxide and } 3 \text { parts } \\
\text { saturated solution of am- } \\
\text { monium oxalate }\end{array}$ & 24 hours & Very slow in its action \\
\hline 8 & ....do.. & $\begin{array}{l}1 \text { part concentrated ammo- } \\
\text { nium hydroxide and } 3 \\
\text { parts saturated solution of } \\
\text { potassium arsenate }\end{array}$ & .....do. & $\begin{array}{l}\text { Very slow in its action. Em- } \\
\text { phasizes the oxide inclu- } \\
\text { sions }\end{array}$ \\
\hline 9 & $\ldots$. do... & $\begin{array}{l}2 \text { parts concentrated ammo- } \\
\text { nium hydroxide and } 3 \\
\text { parts potassium perman- } \\
\text { ganate solution. See } 4 \\
\text { above }\end{array}$ & 2-3 minutes... & $\begin{array}{l}\text { The etching is best carried } \\
\text { out just as the solution } \\
\text { begins to change color to } \\
\text { brown, due to formation of } \\
\text { manganese dioxide. Other- } \\
\text { wise an obscuring film may } \\
\text { result on the specimen }\end{array}$ \\
\hline 10 & Oxidizing acid.. & Nitric acid (sp. gr. 1.42)..... & Very short... & $\begin{array}{l}\text { A satisfactory etch may be pro- } \\
\text { duced, but it is difficult to } \\
\text { control the intensity of the } \\
\text { attack. See Fig. } 2 \text { for the } \\
\text { use of dilute acid }\end{array}$ \\
\hline 11 & ....do. & $\begin{array}{l}\text { Chromic acid, saturated } \\
\text { solution }\end{array}$ & $1-11 / 2$ minutes... & $\begin{array}{l}\text { Emphasizes grain bounda- } \\
\text { ries and also the oxide } \\
\text { inclusions }\end{array}$ \\
\hline
\end{tabular}


TABLE 1.-Typical Etching Reagents for Copper-Continued

\begin{tabular}{|c|c|c|c|c|}
\hline No. & Type & Composition $a$ & $\begin{array}{l}\text { Approximate } \\
\text { etching period }\end{array}$ & Remarks \\
\hline 12 & $\begin{array}{l}\text { Electrochemical } \\
\text { action }\end{array}$ & $\begin{array}{l}2 \text { per cent solution silver } \\
\text { nitrate }\end{array}$ & $20-30$ seconds... & $\begin{array}{l}\text { The film of deposited silver } \\
\text { must be rubbed off. For } \\
\text { this reason the etching } \\
\text { period was determined only } \\
\text { approximately. The pres- } \\
\text { ence of oxide inclusions is } \\
\text { emphasized by the etching }\end{array}$ \\
\hline 13 & & $\begin{array}{l}5 \mathrm{~g} \text { copper-ammonium chlo- } \\
\text { ride, } 120 \mathrm{~cm}^{3} \text { water, con- } \\
\text { centrated ammonium hy- } \\
\text { droxide added until pre- } \\
\text { cipitate which forms re- } \\
\text { dissolves. }\end{array}$ & $30-60$ seconds... & $\begin{array}{l}\text { One of the most satisfactory } \\
\text { etching solutions. See also } \\
\text { Fig. } 3\end{array}$ \\
\hline 14 & & Same in alcoholic solution.. & 2-3 minutes.... & $\begin{array}{l}\text { Unsatisfactory as compared } \\
\text { with the aqueous solution }\end{array}$ \\
\hline 15 & Oxidizing reagent... & $\begin{array}{l}\text { Ammonium persulphate, } 10 \\
\text { per cent solution }\end{array}$ & & $\begin{array}{l}\text { A very satisfactory etching } \\
\text { solution. See also Fig. } 1 .\end{array}$ \\
\hline 16 & do.. & Bromine, saturated solution. & $30-60$ seconds... & $\begin{array}{l}\text { The deposited film may be } \\
\text { removed by immersion in } \\
\text { ammonium hydroxide. The } \\
\text { etching period is approxi- } \\
\text { mate only on account of the } \\
\text { formation of the obscuring } \\
\text { film }\end{array}$ \\
\hline
\end{tabular}

$a$ Aqueous solutions were used unless otherwise stated.

In all cases the method of simple immersion in the solution was followed, except with such solutions as produced a comparatively heavy deposit; for example, silver nitrate and bromine water. The deposit upon the specimen formed by silver nitrate was removed by a swab of cotton and that formed by bromine water by an immersion in ammonium hydroxide. In all cases it is very essential that the two solutions be thoroughly mixed, otherwise some queer misleading results may be obtained, caused by the diffusion currents within the liquid. This is particularly true if the sulphuric acid is added in the concentrated form in making up the acid solutions.

In Fig. I 5 the use of electrolytic etching for copper is illustrated. By proper regulation of the conditions an etching showing very brilliant contrast may be obtained.

An examination of Figs. so to 14, inclusive, each of which illustrates the behavior of one of the different forms of copper used with the same series of etching reagents, shows that, in general, the various forms of copper are affected very similarly by any particular etching solution; for example, silver-nitrate solution 


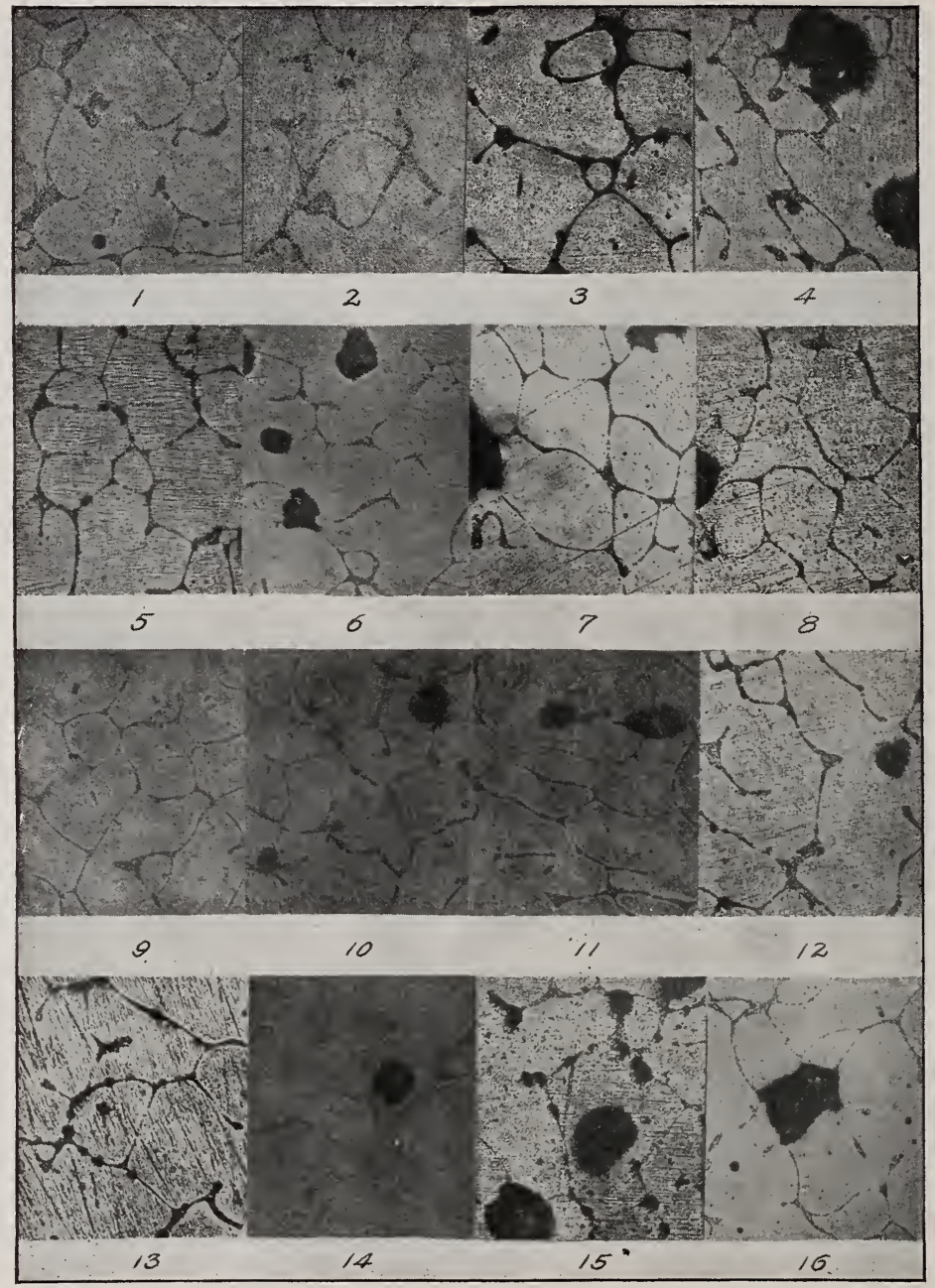

FIG. Io.-Results obtained by etching cast copper with the reagents listed in Table I. Original magnification, $\times 100$, reduced to 75

The number under each micrograph refers to the etching reagent used 


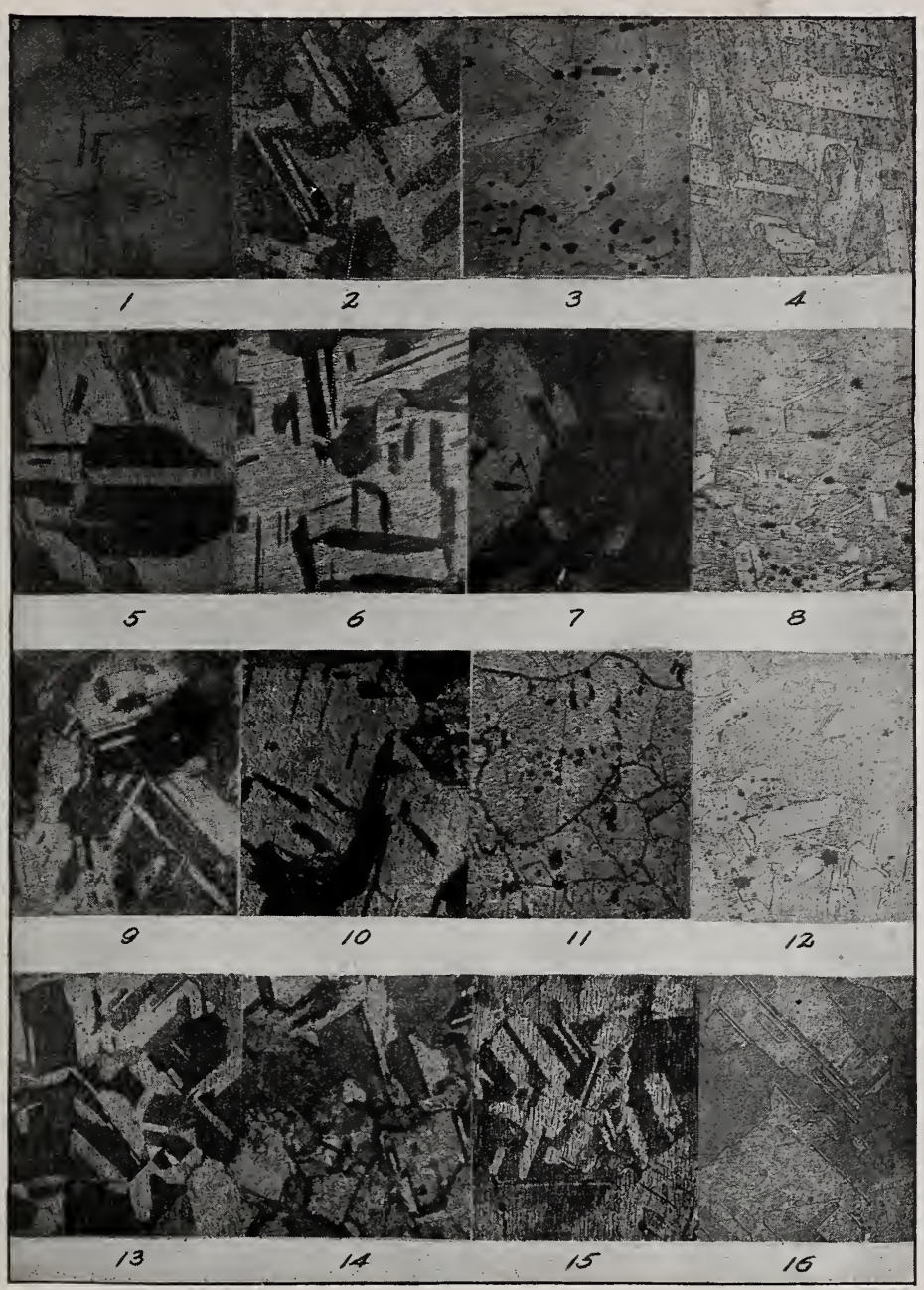

FIG. II.-Results obtained by etching hot-rolled copper with the reagents listed in Table $I$. Original magnification, $\times I 00$, reduced to 75

The number inder each micrograph refers to the etching reagent used 


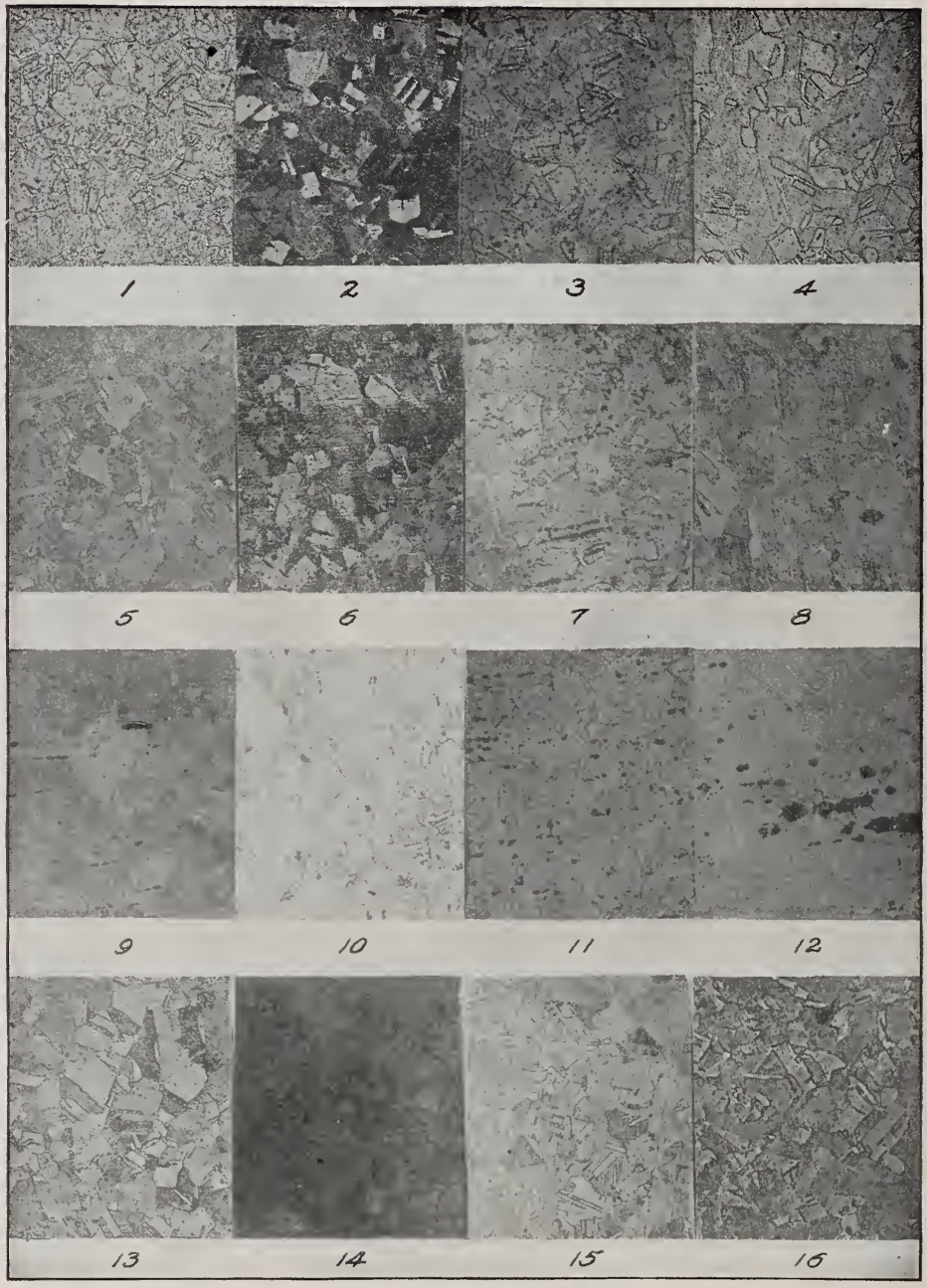

FIG. I2.-Results obtained by etching annealed copper (after cold work) with the reagents listed in Table $I$. Original magnification, $\times I 00$, reduced to 75

The number under each nicrograph refers to the etching reagent used 


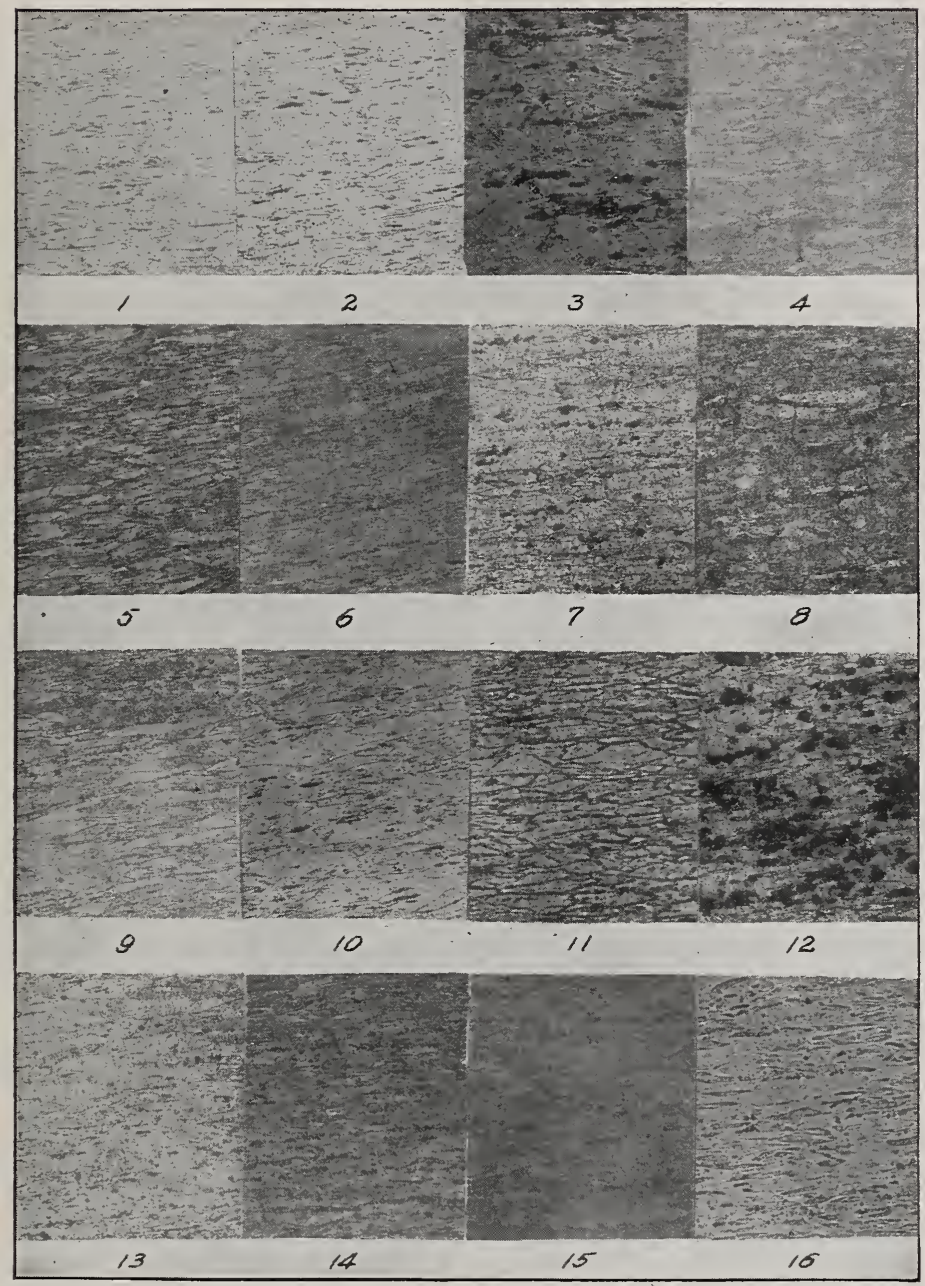

FIG. I3.-Results obtained by etching cold-drawn copper with the reagents listed in Table $I$. Original magnification, XIOO, reduced to 75

The number under each micrograph refers to the etching reagent used 


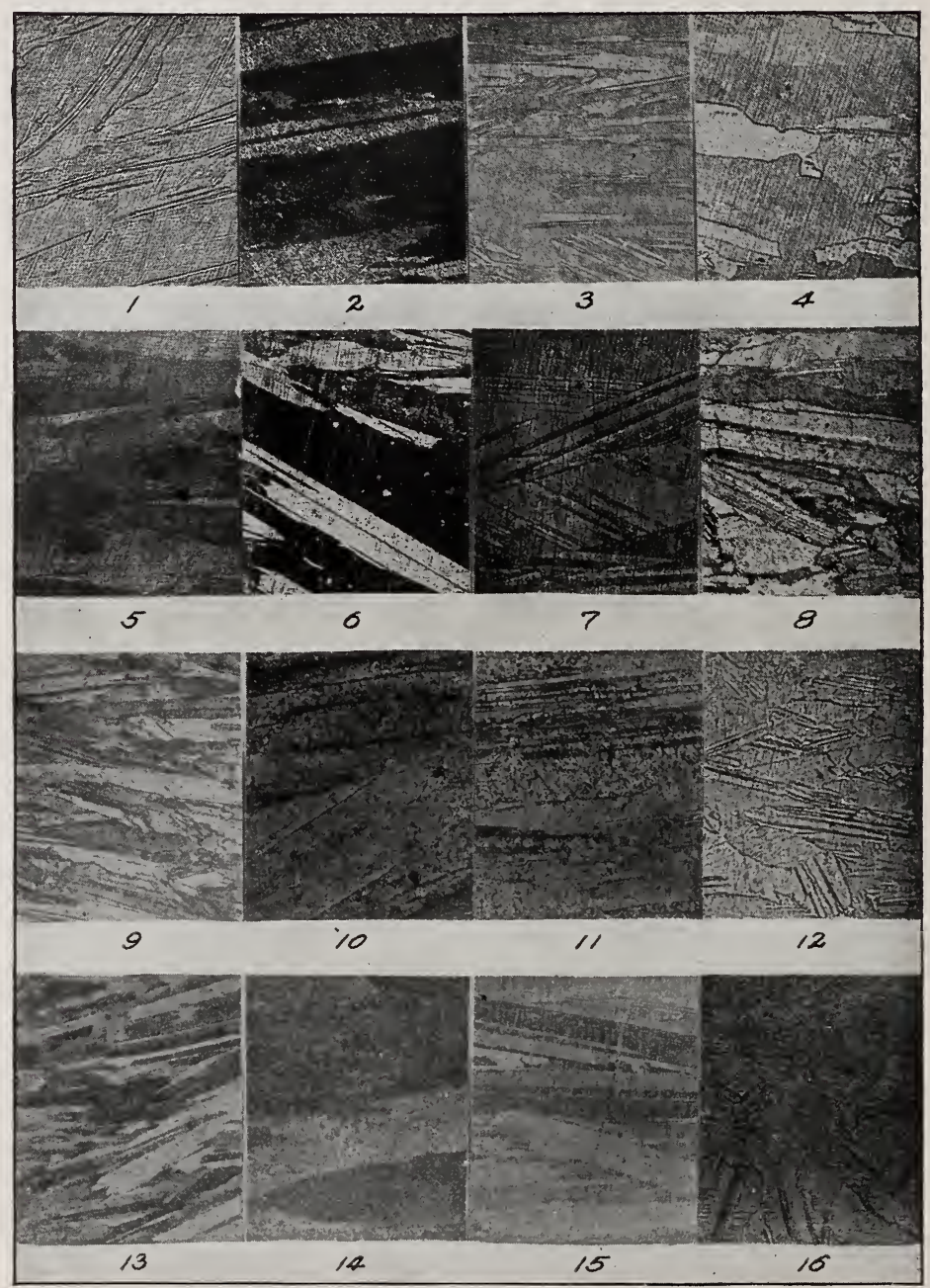

FIG. I4.-Results obtained by etching cathode (electrolytic) copper with the reagents listed in Table I. Original magnification, $\times I O O, r e-$ duced to 75

The number under each micrograph refers to the etching regeant used 
accentuates the presence of inclusions and similar features by causing heavy deposits at such points. Other reagents behave in a characteristic manner on all the specimens. As might be expected, the physical state of the metal affects the rate of etching somewhat; however, this effect is of minor importance as compared to the differences in the rate of etching of the various reagents used.

\section{DISCUSSION}

From the results discussed in the previous sections it is apparent that the dissolving of copper by a solvent is not the simple matter it is usually considered to be, but is accelerated in a pronounced degree by accompanying oxidation. Thus the rate of solution, and incidentally the etching, is fixed by the rate at which oxidation occurs. While it has been known for a considerable time that the corrosion of copper alloys is accelerated by the presence of free oxygen, the value of the application of this fact to the metallographic etching of copper and its alloys does not appear to have been as fully realized as appears to be warranted. The action upon copper by solutions of powerful oxidizing agents alone is probably very similar to that of the weaker solvents through which oxygen is bubbled; for example, the action of ammonium persulphate solution is apparently similar to that of an acid solution and oxygen. In the case of the persulphate the action is very vigorous, however, since the oxygen is utilized at the instant that it is liberated.

The fundamental reaction which occurs when water is added to a persulphate is represented by the following equation:

$$
2\left(\mathrm{NH}_{4}\right)_{2} \mathrm{~S}_{2} \mathrm{O}_{8}+2 \mathrm{H}_{2} \mathrm{O}=2\left(\mathrm{NH}_{4}\right)_{2} \mathrm{SO}_{4}+2 \mathrm{H}_{2} \mathrm{SO}_{4}+\mathrm{O}_{2} \text {. }
$$

A further reaction occurs in the case of ammonium persulphate by which some of the ammonia is oxidized to the form of nitrate, $8\left(\mathrm{NH}_{4}\right)_{2} \mathrm{~S}_{2} \mathrm{O}_{8}+6 \mathrm{H}_{2} \mathrm{O}=7\left(\mathrm{NH}_{4}\right)_{2} \mathrm{SO}_{4}+9 \mathrm{H}_{2} \mathrm{SO}_{4}+2 \mathrm{HNO}_{3}$.

The above equations indicate clearly that the conditions resulting from the decomposition of ammonium persulphate upon the addition of water are essentially the same as those obtained in an acid solution to which an oxidizer is added.

The results obtained with the solutions of copper ammonium chloride show, as has been previously stated, that an oxidizing agent is not always necessary in order to produce a contrast etching. The appearance of the etched surface produced by this reagent shows that the very minute pitting and roughening of the surface is the cause of the brilliant contrast obtained. Owing to 


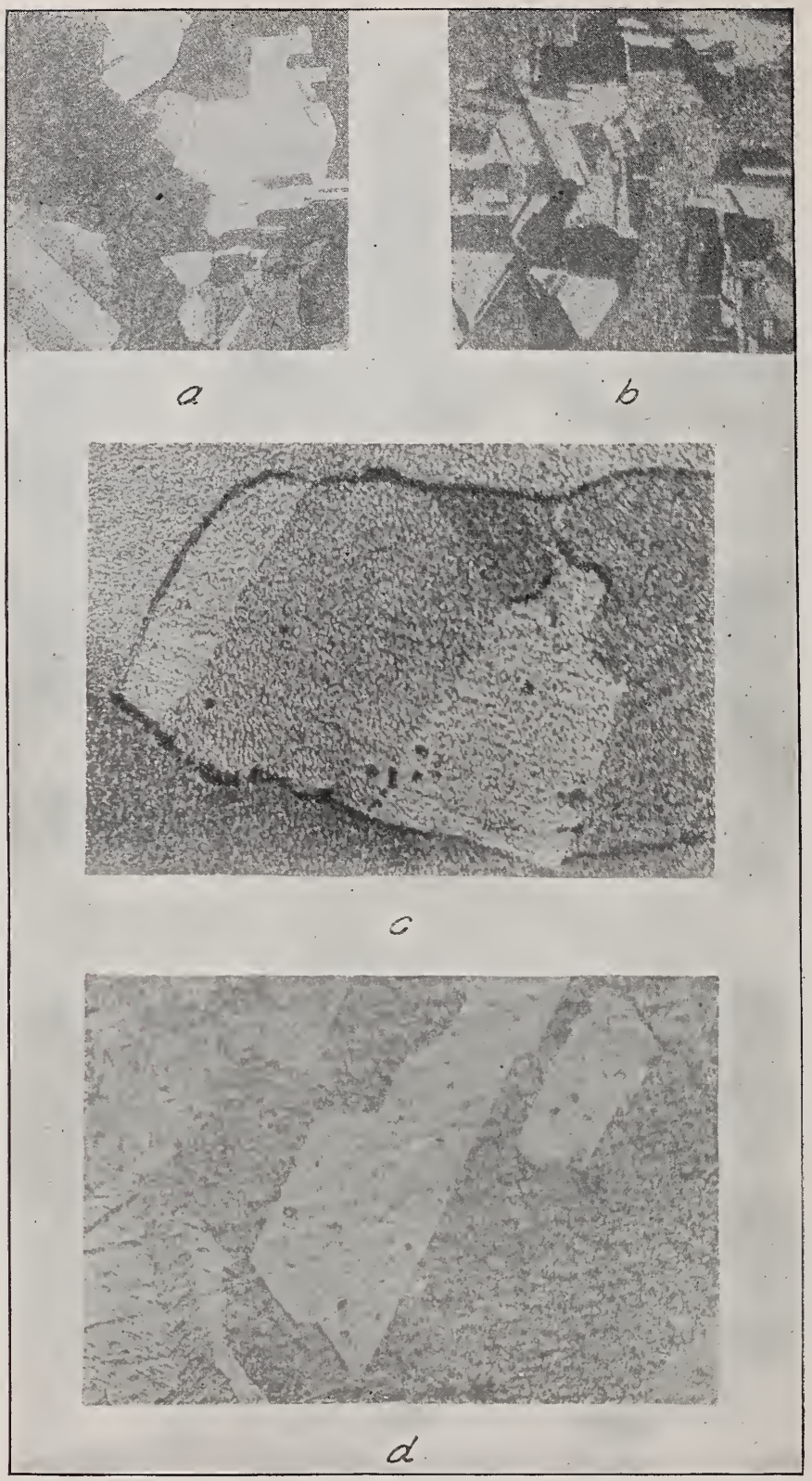

FIG. I5.-Results obtained by etching hot-rolled copper electrolytically. Magnification; " $a$ " and " $b$, " $\times 100$; "c" and " $d$," $\times 500$

Specimens etched in this manner are not well suited for exanination at high magnifications. Ftching conditions: $a$, Flectrolyte, ro per cent solution of ammonium sulphate; cathode, platinum; anode, specimen; current, $0.005 \mathrm{am}$ peres; area of specimen, I. 5 by r. $5 \mathrm{~cm}$.; period, 30 minutes; $b$, conditions same as $a$, except a ro per cent solution of ammonium acetate for electrolyte; $c$, same as $a ; d$, same as $b$ 
the complex nature of this etching solution, however, it is difficult to make a satisfactory explanation of the chemical nature of the etching process other than that it is electrochemical in its action.

In general, the type of etching termed "contrast etching" is most suitable for examination at the lower magnifications, in which case details concerning the grain size, arrangement, etc, are the features to be observed. For examination of the finer details of structure, specimens in which the contrast has been produced by the formation of an oxide film are usually not satisfactory. For such purposes a rather deep etching is required. Some of the reagents discussed, for example, nitric acid, and the mixture of ammonium hydroxide and hydrogen peroxide, attack the metal so readily that the details of structure are obliterated. For such purposes a moderately acting reagent, the action of which can be readily controlled, is best. (Figs. 2, 3, and 4.) Ten per cent copper ammonium chloride solution and ammonium persulphate were found to give excellent results, as did also the acidified solutions of ferric chloride and of potassium permanganate. Electrolytic etching is, in general, very satisfactory for specimens to be examined at low magnifications. (Fig. I 5.) For examination at higher magnifications it is not very suitable. In some cases a pronounced preferential attack along the grain boundaries occurs; there is also a tendency for the electrolytic method to deepen and accentuate preexisting polishing scratches much more than other etching reagents. In Fig. I 5, $c$ and $d$, it may be noted that the pits developed by the etching are quite definitely arranged along the lines of the preexisting polishing marks. The method has the obvious advantage in that the rate of attack can be very readily controlled. Specimens which are etched very slowly, however, are often found to have a dull cloudy appearance. It will be noted that the contrast produced by electrolytic etching is due to the manner in which the different crystals are attacked, which difference is due to the direction in which the sectioning plane passes through the various grains.

There is an advantage sometimes gained by using alcoholic solutions in preparing etching reagents. This is not always true, however, as shown in Figs. Io to I4, inclusive (micrographs I3 and I4). Apparently the hydrochloric acid solution of ferric chloride gives much better contrast when dissolved in alcohol; on the other hand, the alcoholic solution of copper-ammonium chloride is very inferior to the aqueous one. 


\section{SUMMARY}

I. The investigation of metallographic etching reagents in progress at this Bureau is illustrated by a detailed account of the etching of the various forms of copper. This metal was chosen as the first type for consideration on account of its industrial importance as well as because its behavior is typical in a general way of many of the important industrial alloys of copper; that is, the brasses and bronzes.

2. Two general types of etching as defined by the characteristic appearance of the etched surface are described. These are designated as "plain" and "contrast." While many reagents as a rule give but one type of etched surface, it is possible to produce either type, as desired, from some reagents. In general, "contrast" etching is most suitable for microexamination at relatively low magnifications; for study of those features of structure for which high magnifications must be used, the plain uncontrasted etched surface is desired.

3. Oxidation is, in general, of fundamental importance in the solution of copper and consequently in the etching of this metal. Many solutions which have a very slight etching action upon copper may be made to etch readily by passing oxygen through them, but solutions which have no solvent action upon copper can not be made to etch the metal by the addition of oxygen. Ammonium hydroxide in the absence of oxygen has an almost negligible action upon copper. Most of the etching solutions in general use consist of an oxidizer in an acid or an ammoniacal solution. A few very powerful oxidizing agents may be used in solution without the addition of either ammonium hydroxide or acid.

4. As a rule, aqueous solutions are best for the etching of copper; in a very limited number of cases, however, alcoholic solutions appear to give better results.

5. Typical etching reagents are described and micrographs are given to illustrate the characteristic features of each.

WASHINGTON, May 27, 1920. 